\title{
Como e por que fazer de Câmara Cascudo um objeto de pesquisa sociológica?
}

\author{
How and why do a sociological research on Câmara Cascudo?
}

\begin{abstract}
Aluizio Lins de Oliveira ${ }^{a}$
Resumo Realizar uma análise sociológica de uma atividade intelectual implica a construção explicativa das condições sociais de sua produção. O método pede a consideração relacional e a interdependência de elementos que dentro de uma determinada lógica encontram grande parte da fundamentação de suas existências, além da crítica e da reflexividade da própria construção do objeto. A feitura de uma análise sociológica da atividade intelectual de Câmara Cascudo deve trabalhar com duas dimensões que formam uma só, mas se diferenciam enormemente: as relações sociais, culturais e de poder no chamado mundo local e as relações sociais, culturais e de poder nacionais. Além disso, construir analiticamente as diversas fases diferenciadas e os elementos de constância em suas diferentes cores.
\end{abstract}

Palavras-chave atividade intelectual; sociologia; método.

Abstract Carrying out a sociological analysis of an intellectual activity implies the explanatory construction of the social conditions of its production. The method calls for relational consideration and the interdependence of elements that within a given logic find much of the reasoning of their existences, besides the criticism and reflexivity of the construction of the object itself. The construction of a sociological analysis of Câmara Cascudo's intellectual activity must work with two dimensions that form one, but differ enormously: social, cultural and power relations in the so-called local world and national social, cultural and power relations. Also, to construct analytically the various differentiated phases and elements of constancy in their different colors. Keywords intellectual activity; sociology; method.

Para realizar uma construção analítica sociológica da atividade intelectual de Luís da Câmara Cascudo pode-se iniciar pela abordagem de seus livros e artigos publicados, situando-os nos conjuntos culturais em que esses documentos

a Professor de sociologia no Departamento de Ciências Sociais da Universidade do Estado do Rio Grande do Norte. Doutor em Sociologia pela Universidade de São Paulo. Mestre em Ciências Sociais pela Universidade Federal do Rio Grande do Norte. Graduado em Ciências Sociais na Universidade Federal do Rio Grande do Norte. 
surgiram e assumiram certas particularidades. Este ou qualquer outro ponto da atividade intelectual pode receber as considerações dos aspectos mais gerais, históricos e estruturais da vida social em seus diversos níveis de modo a explicitar os contornos que possibilitem o melhor desenho dos detalhes do caso. Isso representa um programa de pesquisa de longo prazo. Contudo, podemos buscar a construção de uma explicação geral da trajetória de Cascudo e passar para a atenção sobre suas diversas fases e partes, que podem constituir diversas construções sociológicas em cada uma delas.

Assim, pode-se fazer já algumas indicações ou registros cronológicos com o intuito de apontar diversos quadros numa trajetória que pode ser desenhada em um quadro maior. Um primeiro panorama da fixação investigativa do caso pode ser indicado pelos seguintes registros: a formação escolar de Cascudo em Natal nas décadas de 1910 e 1920; o início dos cursos superiores em 1918, matriculando-se no curso de Medicina, em Salvador; o início de publicações de artigos em jornal do pai, A Imprensa, também em 1918; a publicação do primeiro livro em Natal, em 1921; o início dos contatos com Mário de Andrade através de cartas em 1924 e se estendendo por quase duas décadas ${ }^{1}$; a aproximação com o movimento do modernismo paulista na década de 1920, bem como com intelectuais de Recife que se vinculavam ao modernismo; a ativa participação no movimento Integralista na década de 1930; a publicação do primeiro livro enquadrado na dimensão folclorista em 1939, depois de livros de crítica literária, biografias políticas (como a sobre o paraguaio Solano Lopez), uma antologia de poeta potiguar e outro em que narra uma viagem pelo interior do Rio Grande do Norte em 1934; o cargo na estrutura do Estado $\mathrm{Novo}^{2}$; a sequência das publicações sobre o folclore que se estenderam até a década de 1970; a publicação de um Dicionário do Folclore Brasileiro em 1954, com reedições nas décadas de 1960 e 1970; as várias viagens ao estrangeiro vinculadas ou não a atividades de representação nacional ou financiadas para pesquisa, como a viagem à África para uma pesquisa sobre a alimentação brasi-

1 Cascudo, como outros intelectuais brasileiros do período, fez uso constante da comunicação por cartas durante toda a sua vida e há um volumoso material hoje de posse do Instituto Câmara Cascudo, em Natal, gerido por seus descendentes. Em 2010, foi publicado um volume mais completo da correspondência de Cascudo com Mário de Andrade (Cascudo; Andrade, 2010). Antes, em 1991, um amigo de Cascudo, Veríssimo de Melo, que fez parte do grupo de folcloristas de Natal, capitaneado por Cascudo, organizou uma primeira edição dessas cartas (MeLo, 1991). Depois, em 1999, uma dissertação de Mestrado na Universidade Federal do Rio Grande do Norte finalizou um novo levantamento importante sobre esse material (Gomes, 1999).

2 Sergio Miceli indica que os "ganhos posicionais de integralistas se fizeram sentir em praticamente todas as frentes especializadas do mercado central de postos”. E entre vários nomes cita o de "Luís da Câmara Cascudo (ex-membro da Câmara dos Quatrocentos), presidente da Comissão de Salário Mínimo da 6a região, Natal, Rio Grande do Norte (1941)” (Miceli, 2001, p. 276). A Câmara dos Quatrocentos fazia parte da estrutura organizativa da Ação Brasileira Integralista. 
leira, na década de 1960, financiada por instituto ligado a Assis Chateaubriand; a publicação de livros sobre a história do Rio Grande do Norte nas décadas de 1940 e 1950; de biografias sobre algumas personagens dessa história local na década de 1960; de livros memorialísticos no final da década de 1960 e inícios da de 1970, etc. Toda a produção intelectual de Cascudo pode ser considerada a partir de duas grandes áreas temáticas: sobre pessoas e fatos do Rio Grande do Norte e sobre o folclore brasileiro, sendo que as publicações caracterizadas na perspectiva folclórica assumem dimensão dominante e constituem fator de fixação de uma posição no mercado intelectual nacional.

Uma questão que pode se colocar de início é o que se pretende com um tipo de estudo que se quer sociológico e anuncia a consideração de uma individualidade. O indivíduo é identificável no quadro do que se observa como real, mas pelo olhar sociológico só pode ser concebido porque componente de uma vida social e viabilizado por uma cultura histórica e socialmente construída. Na compreensão científica da sociedade, quanto mais se aprofunda a análise da individualidade, mais aparecem as estruturas sociais. $O$ agente tomado individualmente num exercício de abstração põe em ação essas estruturas das quais é parte inseparável e das quais deriva e ativa sua razão de ser. Um quadro histórico expressa a especificidade das relações onde o que é tomado individualmente revela um sentido ${ }^{3}$. Na individu-

3 Dois estudos podem ser citados aqui, como exemplos de análises sociológicas que mantêm o registro de uma individualidade. O de Norbert Elias (1995) sobre Mozart e o de Leopoldo Waizbort (2000) sobre Georg Simmel. Elias desenvolve a explicação das mediações de elementos interdependentes, enfatizando a importância da análise sociológica para a compreensão de um caso aparentemente individual: "O destino individual de Mozart, sua sina como ser humano único e portanto como artista único, foi muito influenciado por sua situação social, pela dependência do músico de sua época em relação à aristocracia da corte. Aqui podemos ver como, a não ser que se domine o ofício de sociólogo, é difícil elucidar os problemas que os indivíduos encontram em suas vidas, não importa quão incomparáveis sejam a personalidade ou realizações individuais - como os biógrafos, por exemplo, tentam fazer. É preciso ser capaz de traçar um quadro claro das pressões sociais que agem sobre o indivíduo. Tal estudo não é uma narrativa histórica, mas a elaboração de um modelo teórico verificável da configuração que uma pessoa - neste caso, um artista do século XVIII - formava, em sua interdependência com outras figuras sociais da época.” (ELIAS, 1995, p. 18-9). Waizbort, no extenso e variado painel que expõe sobre Simmel, sempre lembra a importante compreensão da interação que o próprio Simmel inicia enquanto proposição analítica e que será bastante desenvolvida em várias modalidades por diversas elaborações da sociologia norte-americana. "Simmel mostra [...] de que natureza é o tecido das relações que ele tem em vista. Trata-se de um jogo. É por isso que M. Landmann 'traduziu' Wechselwirkung como 'interação circular', pois se não há circularidade o todo não se tece e os caminhos que Simmel percorre nunca poderiam ser percorridos. Simmel elabora uma rede de interações que forma um labirinto. Sua sensibilidade aguçada permite-lhe circular por entre o labirinto com a segurança do ensaio e da tentativa, nunca com a segurança do sistema. Os caminhos que ele percorre incessantemente são os fios dessa teia, que ele vai tecendo à medida em que se movimenta. [...] Tecer relações, atar fios e penetrar o impenetrável são aventuras, Simmel o aventureiro. Em Simmel a unidade, e portanto o todo, consiste na interação das partes. Como a interação é sempre e principalmente uma relação mútua e múltipla, e que se estende infinitamente, o resultado disso é que o todo está sempre em processo, móvel, é um tecido que se tece continuamente. É nesse sentido que disse que, de relação em relação, o mundo de Simmel 
alidade corporal e emocional também está condensada algumas características da vida social e histórica que a definiu e a define em muitos espaços e momentos. E o grau de expressão que uma pessoa pode conter pelo trabalho que sobre ela exerça uma representação social levado a efeito por diversos agentes em determinado momento eleva o grau de visualização do social na unidade aparente do individual.

A escolha de uma individualidade é anunciada no título deste artigo, mas já expressando uma função de redução analítica e de construção de objeto de estudo. Um segundo passo é quando se define a vida intelectual de Luís da Câmara Cascudo pelas suas atividades de escritor de livros e artigos, sua formação escolar e curso superior de direito, sua prática da advocacia, bem como suas atividades como professor. As condições sociais dessa produção intelectual são objetivadas primeiramente na própria prática do escritor. Uma prática cultural cultivada na leitura de livros, jornais e revistas; no gosto de estar com os livros, de vê-los numa estante, como disse certa vez; no aprendizado de línguas estrangeiras, principalmente do francês e do inglês, mas também do latim; no amor à literatura e na valorização da crítica literária; na atividade de ensino de história; na publicação de livros e artigos em jornais e revistas, etc.

Como se vê, nesse conjunto de atividades, já se percebe a limitação da compreensão a partir de uma dimensão de individualidade em uma forma isolada e essencialista. Essa produção intelectual, então, se apresenta como uma operação social de cultura e de distinção social, com posições hierárquicas e ligada por diversas mediações ao conjunto das relações sociais e de poder ${ }^{4}$. Apresenta-se desde o início como um capital social nos níveis locais e nacionais, ganhando um peso

torna-se um mundo de relações." (WAIZBORT, 2000, p. 100-1). É possível observar uma foto de Simmel na página 412, e em outros momentos Waizbort registra inclusive posturas corporais individuais de Simmel. Esses elementos podem ajudar na compreensão sociológica de uma individualidade, porque também apontam para um conteúdo social da vida corporal do indivíduo. Waizbort define também uma parte com o título "O indivíduo como ponto de cruzamento dos círculos sociais”, e desenha três gráficos com nomes de pessoas e grupos circulados e ligados por traços com o do Simmel, dando expressão a um emaranhado circular de relações sociais. Os gráficos são nomeados: "Georg Simmel como ponto de cruzamento das relações sociais." (WAIZBORT, 2000, p. 489-490).

4 Aludo aqui à sociologia de Bourdieu (2010) e a construção do objeto que realiza, por exemplo, no livro A distinção: crítica social do julgamento de gosto. O estudo dos elementos que compõem as condições sociais e culturais das definições do gosto para uma série de atividades e sensibilidades se refere às estruturas sociais francesas na década de 1960 e 1970. A atividade cultural é construída na investigação como componente de definição das estruturas sociais relacionais e variadas, compreendida como capital na forma social da sociabilidade das relações de classe e de dominação material-simbólica. Assim, contribui no sentido de justificar socialmente e naturalmente a existência social das distinções e dos estratos diferenciados nas suas múltiplas gradações no interior das grandes e tradicionais estratificações de setores superiores, médios e inferiores. 
maior no mundo local, inclusive através de ações no nível nacional ${ }^{5}$. A referência a um nome não significa que a investigação queira realizar uma "biografia", pelo menos no sentido da concepção corrente sobre esse tipo de literatura. O nome da pessoa implica um tipo social muito situado numa divisão social de atividades e numa estrutura social que, inclusive, se desenhava e redesenhava antes do seu nascimento. Na verdade, o nome da pessoa e, dessa forma, a própria pessoa deste exemplo, como em todos os casos de certos tipos de pessoas individuais, não cessa de nascer, inclusive depois de sua existência biológica. Isso reafirma a perspectiva analítica de construção explicativa de espaço, tempo e história social ${ }^{6}$. Entretanto, esse trabalho de construção explicativa, que pode ser visto como teórica, deve vir junto do raciocínio sobre a prática. Trata-se de um racionalismo aplicado como o desenvolvido a partir de Gaston Bachelard. O sociólogo Bourdieu, que faz muitas referências a este filósofo, particularmente nas suas abordagens sobre a formação do pensamento científico, oferece uma expressão nova para o entendimento da teoria. Exemplo disso é o momento em que chama por uma teoria que está em todo o lugar e em lugar nenhum.

Na mesma medida em que me desagradam essas profissões de fé pretensiosas de pretendentes ávido de sentar-se à mesa dos "pais fundadores”, deleito-me com essas obras em que a teoria, porque é como ar que se respira, está por toda

5 Como avalia um estudioso local: "durante a década de quarenta o escritor Câmara Cascudo marcou sua presença na imprensa local publicando assiduamente a coluna 'Acta Diurna' e editando livros que lhe deram muita popularidade e respeito intelectual. Aquele período significou o início de sua ascensão como historiador e folclorista." (SouzA, 1984, p. 26). No meu trabalho de doutorado registrei e apontei o Rio de Janeiro e a editora José Olympio como o local e a editora onde Cascudo publicou a maioria dos seus livros.

6 As ciências sociais já produziram considerações muito fundamentais sobre a relação indivíduo/sociedade. Podemos lembrar a discussão em Durkheim e Mauss, indicando para os fundamentos culturais de nossa própria representação da pessoa (MAUSs, 2003). A sociologia weberiana, por sua vez, trabalha a identificação das relações e das ações sociais se afastando de determinações unitárias. Elias também tem um livro dedicado a discutir as compreensões sobre a relação indivíduo e sociedade (ELIAS, 1994), mostrando as posições dos que explicam a realidade pelo indivíduo e pela sociedade e construindo a proposta que supera as duas vias: as redes que se tecem permanentemente, os passos orquestrados da configuração, as explicações que só se completam quando vão buscar longe os vetores que atingem os elementos das redes, etc. Bourdieu já aponta o total afastamento dessa questão e da consideração das relações e de como se estabelecem suas forças relacionais, além de avançar pela concepção dos mercados de bens simbólicos, construída em investigações ao mesmo tempo teóricas e empíricas. O livro de Goffman, apesar da referência ao "self" no título, não foge a essa tradição, como se vê no desenvolvimento de suas análises e em suas considerações conclusivas questionadoras (GoFFMAN, 1999): o social não é um teatro; a dramaturgia com a qual faz analogias é apenas um recurso de método; não é o caso fornecer aos agentes a melhor forma de viver um papel e sim compreender melhor os fundamentos da vida social; o momento da interação está ligado a circuitos maiores. Finalmente, um texto de Wacquant que sistematiza a perspectiva de Durkheim destaca o papel da ciência em superar as evidências e buscar as relações impessoais (WACQuANT, 1995). Aparece nestas análises também as identificações das forças que agem nos processos relacionais que conformam e desenham constantemente a identificação e a existência das individualidades. 
parte e em parte alguma, no meandro de uma nota, no comentário de um texto antigo, na própria estrutura do discurso interpretativo. Reencontro-me completamente nesses autores que sabem abarcar as questões mais decisivas em um estudo empírico minuciosamente conduzido e fazem dos conceitos um uso a um só tempo modesto e mais aristocrático, chegando por vezes a ocultar sua própria contribuição em uma reinterpretação criativa das teorias imanentes ao seu objeto (BOuRDIEU, 1996, p. 204).

Trata-se de realizar um novo espírito científico nas ciências sociais. A expressão "novo espírito científico" se liga primeiramente as elaborações de Bachelard, que analisa as mudanças na física no início do século XX, como prova da necessidade da construção explicativa, contrariando a tradicional visão racionalista da objetividade (BACHELARD, 1996 e 2008). Comparando com as análises do romance moderno que realiza Auerbach, Bourdieu esclarece que isso implica uma desarrumação e anulação das hierarquias de legitimidade na escolha de objetos válidos para a investigação.

Pedir a solução de um problema canônico a estudos de caso [...] É infligir à hierarquia tácita dos gêneros e dos objetos uma transformação que não deixa de estar relacionada com a que operam, segundo Erich Auerbach, os inventores do romance moderno, Virginia Woolf especialmente: "Confere-se uma importância menor aos grandes acontecimentos exteriores e aos golpes da sorte, considerados menos capazes de revelar alguma coisa de essencial a propósito do objeto examinado; acredita-se, em compensação, que qualquer fragmento de vida, tomado ao acaso, não importa quando contém a totalidade do destino e pode servir para representá-lo”. É uma transformação semelhante que é preciso operar para chegar a impor nas ciências sociais um novo espírito científico: teorias que se alimentem menos da defrontação puramente teórica com outras teorias que do confronto com objetos empíricos sempre novos; conceitos que antes de tudo têm por função indicar, de maneira estenográfica, conjuntos de esquemas geradores de práticas científicas epistemologicamente controladas (Bourdieu, 1996, p. 204).

As dificuldades iniciais de uma pesquisa são de naturezas diversas e podem ser superadas de diversas formas. Durkheim indicou um caminho inicial para o processo do conhecimento científico quando afirmou que "no começo da pesquisa só as exterioridades nos são acessíveis" (DurkHEIM, 1994, p. 67). As aparências não nos fornecem a compreensão, mas é um passo mais evidente e realizável registrar 
o que vai aparecendo como coisas exteriores. Essas coisas exteriores aparecem para os agentes que a vivenciam, como $a$ realidade, o que pode ser superado pelo confronto com a linguagem nativa e as significações que podem afetar as próprias descrições do pesquisador. Por outro lado, existem referências implícitas teóricas e metodológicas desde o início da pesquisa, já presentes nessas primeiras aproximações. No entanto, temos que procurar a perspectiva da superação de dualidades como externo/interno, subjetivo/objetivo, teoria/prática, agente/estrutura, exterioridades/essências. Então, a própria referência a essas exterioridades implica vetores que vão além das composições formais. Considerando isso e aceitando essa porta de entrada podemos nos aproximar pelas exterioridades e ao mesmo tempo nos orientarmos por uma determinada lógica. Por exemplo, nesse caso, a definição da inserção da atividade intelectual no meio histórico e nas estruturas hierarquizadas, conflituosas e com relações de poder que já se tem em consideração desde o início da abordagem do caso empírico. Bourdieu explorou largamente esses elementos em suas críticas ao estruturalismo e a filosofia do sujeito.

O objetivo de testar a sociologia no sentido em que estamos desenvolvendo, numa específica construção explicativa de um caso particular permite que se aplique alguns conceitos, confrontando-os com o objeto construído, os reformulando e mesmo que se crie novos conceitos necessários ao trabalho de descobertas. Por exemplo, o conceito de campo intelectual exige duas considerações iniciais: o conceito de campo social como exercício prático de pesquisa e a visão relacional do real, que já se faz presente nas análises científicas de diversas áreas. Mas os conceitos não são considerados fora da aplicação no caso. Na construção do objeto proposto, na relação em análise entre uma atividade de publicação e o corpo social como um todo em suas múltiplas determinações culturais e políticas, o campo intelectual não se apresenta com fronteiras nítidas e se mistura às determinações inerentes às outras esferas sociais.

Considera-se Câmara Cascudo inicialmente na posição de um produtor de textos escritos publicados em jornais e livros que se tornou um importante ponto de referência e reverência no meio social local e conhecido como folclorista e erudito no mercado cultural nacional. Visualiza-se o agente como expressão das características de funcionamento dos estratos intelectuais situados nos grupos dominantes da sociedade local do Rio Grande do Norte. Os processos que definem essa posição revelam íntimas relações com o campo de poder estatal e com as sociabilidades aparentemente pessoais e impessoais praticadas no interior dos grupos dirigentes. A compreensão disso, além de outros elementos, exige um desenho da 
configuração relacional (EliAs, 1994)7, que ajuda a observar o tipo de produção escrita e de sua publicação e das práticas sociais e bens simbólicos que circularam nesse campo específico em relação às variadas determinações políticas e culturais da sociedade ${ }^{8}$. E uma construção analítica que compreende as condições sociais e culturais em que esses bens simbólicos se tornaram capital simbólico. Construir a realidade com a ferramenta compreensiva do campo social implica trabalhar com as categorias de capital simbólico, bens simbólicos, habitus, bem como com as frequentemente menos abordadas de poder simbólico e violência simbólica. Valorizar imprescindíveis conceitos forjados numa pesquisa que reúne de forma inseparável teoria e prática, em que a obra de Bourdieu é a mais forte expressão, não desautoriza a abertura para a criação de novos conceitos ou modificações de conceitos já existentes, retificando ou complementando sua significação. Não se pode perder de vista o caráter provisório das armações conceituais necessárias para levar à frente as investigações, nem o permanente trabalho de teste e de criação de novas perspectivas dos próprios conceitos ou mesmo de novos conceitos a serem criados no processo de pesquisa. Esse é mais um pressuposto de uma sociologia crítica e reflexiva e que torna viável a ciência social.

Empreender uma análise sociológica é compor uma criação explicativa pelo processo de construção do objeto de pesquisa. Essa criação aparece como uma construção nova da realidade e significa que se monta uma explicação que não existia anteriormente porque não era assim considerada pelos agentes envolvidos ou exteriores aos fatos. Implica o trabalho de montagem de conceitos dentro duma linguagem relacional, que realiza um discurso de expressão de um real que antes não se apresentava daquela forma e assim não existia, nem para os agentes, nem para o processo de conhecimento que o queria compreender. Trata-se, por exemplo, de uma busca da construção de redes relacionais em que cada ponto contém partes dos outros e se explicam apenas em sua mutualidade. Junto a todo esse exercício um outro é fundamental: a perspectiva reflexiva abordando as condições sócio-culturais que envolvem a pesquisa e o pesquisador buscando a compreensão sobre as características que envolvem o ato de compreender ${ }^{9}$.

7 As obras de Elias sobre a sociedade de corte (Elias, 2001), sobre o processo civilizatório da modernidade europeia (ELIAS, 1994a), sobre os alemães no século XIX e XX (ELIAS, 1997), entre outras, são exemplos de aplicações práticas da compreensão configuracional.

8 Sergio Miceli faz rica sistematização das análises da determinação na sociologia de Norbert Elias em um Dossiê Norbert Elias organizado por Leopoldo Waizbort (MicELI, 2001a).

9 No livro A Miséria do mundo, coordenado por Bourdieu, que reúne entrevistas com diversas pessoas, precedidas por considerações que procuram compreender as forças sociais que agem nos casos particulares, a perspectiva do compreender é nuclear. Novamente a reflexividade é abordada em uma seção final sobre indicações metodológicas: "Só a reflexividade, que é sinônimo 
A atividade intelectual aqui é percebida como uma dimensão da atividade cultural geral. Quer dizer, o que pode ser visto como uma atividade técnica se realiza numa especialização que está sempre atada a várias ramificações da estrutura social. O materialismo histórico e dialético de Marx, que marcou o pensamento e a história ocidental contemporânea, desenvolveu-se alimentando a explicação da sociedade pela determinação da cultura pelo modo de produção material da sociedade. As dimensões e atividades culturais foram consideradas epifenômenos da base material econômica e como tal não seriam alvos fundamentais de preocupação explicativa. Um conjunto maior da tradição sociológica a partir de Durkheim e Weber e a matização dessa análise dentro da tradição do materialismo histórico e dialético que significou as elaborações de Antonio Gramsci e da chamada teoria crítica da sociedade, focalizou de forma diferente o papel da esfera cultural na própria explicação sobre a produção e reprodução da sociedade. As contribuições dos chamados estudos culturais dos ingleses como Raymond Williams e Edward Thompson revelam-se como um indicador dessa tendência e dessa problemática.

Por outro lado, a presença social dos espaços estudados como culturais, como o jornal, o rádio, a televisão, o cinema, etc, e as possibilidades das realizações das mensagens e da organização dos grupos, como artistas e religiosos, bem como sua organização mercadológica como indústria cultural, desenvolveu-se enormemente nas fases recentes das sociedades capitalistas. Isso também se refletiu nas discussões científicas da sociologia. Esses caminhos foram ampliados com as sociologias de Norbert Elias e Pierre Bourdieu, refletindo também um campo intelectual mais complexo ou de maior autonomia relativa. Por outro lado, Bourdieu, que reorientou o caminho da sociologia, apontou para a superação dessa dicotomia e do determinismo da economia em relação à cultura e elaborou sobre a existência de um mercado de bens simbólicos. Maria Arminda do Nascimento Arruda ilustrou essa discussão, colocando de lado por um instante o método para cativar uma audiência, dizendo que se Marx estivesse pensando esse mundo da segunda metade do século XX em diante era para os elementos de cultura que iria se voltar mais intensamente.

de método, mas uma reflexividade reflexa, baseada num 'trabalho', num 'olho' sociológico, permite perceber e controlar no campo, na própria condução da entrevista, os efeitos da estrutura social na qual ela se realiza. Como pretender fazer ciência dos pressupostos sem se esforçar para conseguir uma ciência de seus próprios pressupostos? Principalmente esforçando-se para fazer um uso reflexivo dos conhecimentos adquiridos da ciência social para controlar os efeitos da própria pesquisa e começar a interrogação já dominando os efeitos inevitáveis das perguntas" (BourdiEU, 1997, p. 694). 
Os processos posicionais que localizam o produtor de textos Câmara Cascudo em quadros de ordem hierárquica estabelecem constantes relações com o campo de poder estatal e com as sociabilidades praticadas no interior dos grupos dirigentes. Na sociedade local do Rio Grande do Norte o campo de poder estatal envolve todos os aspectos da vida e das possibilidades de resolução para os problemas que os indivíduos enfrentam, desde a formação cultural em todos os seus aspectos, até a sobrevivência biológica e as condições materiais em geral ${ }^{10}$. Podemos identificar a posição de Cascudo como fazendo parte das sociabilidades dos dominantes e um degrau abaixo do núcleo principal. Por exemplo, nas suas primeiras fases de vida, na primeira república brasileira, temos a amizade do seu pai com Pedro Velho, o "chefe supremo" no poder local, como escreveu Cascudo. Por outro lado,

10 Um exemplo: um livro publicado em Natal em 1988 sobre a Faculdade de Direito de Natal contém no prefácio escrito por um dos seus professores a seguinte observação: "Na sua história [o autor] descreve, com minúcias, a sucessão curiosa de professores de uma escola ainda por funcionar, suas nomeações e exonerações pelos governadores do Estado. Tudo decorrente das querelas da sempre agitada política partidária do Rio Grande do Norte, que se reflete nos mais diferentes e insuspeitados setores. Cada governador que ascendia, nesse período, promovia alterações no quadro do professorado, segundo os ventos políticos. Escapavam das mudanças, de um modo geral, apenas aqueles não comprometidos nas disputas político-partidárias. Meu nome, por exemplo, ficou conservado desde a primeira nomeação.” (GuANABARA, 1988, p. 10). A Faculdade de Direito de Natal começa a funcionar em 1954. O prefácio foi escrito por Otto de Brito Guerra e uma consulta rápida a um registro biográfico revela permanentes relacionamentos e ocupações que constituem fatores para um incremento do aumento do seu peso relativo no conjunto das relações sociais produzindo essa situação em que "escapava" das mudanças pessoais nos cargos pontuados pelas relações de poder. Também revela a existência de muitas relações políticas, longe desse não comprometimento expresso no excerto. "Ainda estudante de Direito, Otto Guerra deu os primeiros passos em busca de afirmação profissional, lecionando Desenho no Colégio Pedro II, e trabalhando como revisor do 'Diário de Natal'. Formado pela Faculdade de Direito do Recife, iniciou sua vida pública como Chefe de Gabinete e Secretário do Interventor Mário Câmara (19331935). Ocupou, sucessivamente, os seguintes cargos e funções: $2^{\circ}$ Promotor Público de Natal (1935), Delegado Seccional do Serviço Nacional de Recenseamento, Consultor Jurídico e Diretor do Departamento das Municipalidades, Diretor do Departamento Estadual de Reeducação e Assistência Social, Procurador Geral do Estado, no governo Dix-Sept Rosado, Chefe da Seção de Assistência Judiciária da LBA e Superintendente interino desta entidade, no Rio Grande do Norte (1945). Em 1948, tornou-se Procurador e advogado da Caixa Econômica Federal do Rio Grande do Norte, cargo em que, anos depois, aposentou-se. Firmando-se como advogado, teve destacada atuação, notadamente na defesa de presos políticos, durante a ditadura militar pós-64. Não menos importante foi sua atuação no magistério: professor de vários colégios de Natal e dos seguintes estabelecimentos de ensino superior: Escola de Serviço Social, Faculdade de Filosofia, Ciências e Letras de Natal, Escola de Sociologia e Política da FJA e Faculdade de Direito da UFRN, da qual foi diretor. Por três vezes exerceu o cargo de Vice-Reitor da UFRN. Jornalista e líder católico, particularmente interessado na difusão da doutrina social da Igreja, Otto Guerra deixou, dispersos, inúmeros artigos e ensaios sobre os mais variados assuntos, dentre estes, em especial, a problemática social nordestina. Durante muitos anos, foi diretor do jornal católico 'A Ordem' e colaborou na Emissora de Educação Rural e noutros órgãos da imprensa natalense, como ‘Tribuna do Norte', 'A República' e 'Diário de Natal'. Quando jovem teve uns namoros com a política, chegando a candidatar-se, uma vez a Deputado Estadual, pela Ação Integralista Brasileira, e outra a Senador, pelo PTB/PRP, sem todavia conseguir eleger-se. Pertenceu a diversas instituições culturais e religiosas, e foi, por nomeação do Papa Paulo VI, Consultor da Comissão Pontifícia Pós-Conciliar, para Comunicações Sociais, com sede em Roma. Dentre outros títulos honoríficos, recebeu a comenda da Ordem de São Gregório Magno, no grau de cavaleiro, concedida pelo Papa Pio XII.” (CARdoso, 2000, p. 605-6). 
o trabalho de produção de publicações de Cascudo só pode ser compreendido se levarmos em conta os meios intelectuais brasileiros em seus variados círculos, e particularmente a sua relação com alguns desses. O tipo de escrito que produz para ser publicado nos jornais locais é totalmente diferente nos temas e modalidades daqueles publicados para a circulação no mercado nacional de jornais e de livros. O que aparece como primeiro indicador de uma dupla inserção em dois universos institucionais diferentes, embora fazendo parte de uma mesma totalidade.

A pesquisa deve, então, se ocupar com diversas instituições que definem um quadro de relações mutáveis e permanentes para períodos curtos e longos, onde a atividade intelectual e as modalidades em que ela se realizou possam ser melhor compreendidas. Nisso, além das pesquisas do mundo local e nacional a partir das questões da produção intelectual, é preciso fazer o vínculo do caso específico com as questões que circulam na sociologia da cultura, que também inclui uma sociologia do conhecimento e uma sociologia da educação. Processo que deve andar colado aos passos da coleta de todos os elementos necessários para a melhor construção do específico.

O grande erro que aparece de forma permanente nos trabalhos que pretenderam analisar a vida e/ou a obra de Câmara Cascudo é que o tomaram como um dado da cultura e não como um problema de cultura, de uma cultura específica ${ }^{11}$. O que aparece já resolvido é, na verdade, um problema de cultura. E não basta afirmar que se trata de uma cultura elitista, hierarquizada e hierarquizante, dividida e divisora, diferenciada e diferenciadora, que escamoteia os processos e as partes de um sistema cultura em sintonia com os complexos processos de dominação social, onde se pode construir um problema sociológico em relação à figura de Cascudo. É preciso definir as relações e os processos, os quadros de posições, as fases e seus aspectos constantes e mutáveis, os diferentes níveis de abrangência dentro de uma sociedade onde espaços locais, regionais e nacionais

11 A maior parte dos trabalhos que comentam Cascudo são apologéticos, mesmo os que não se realizaram com objetivos de homenagem e louvor. Nos anos mais recentes algumas análises se fizeram no interior da universidade, mas não desataram os ligamentos com os trabalhos tradicionais dos agentes de produção da representação social de Cascudo. São diversas as publicações de homenagens, desde a década de 1940 (Melo, 1947). Mamede (1970) E Gico (1996) publicaram livros com os registros bibliográficos da produção de Cascudo. O trabalho de Zila Mamede se estende desde o início das publicações (1918) até o final da década de 1960. Vânia Gico também realizou um trabalho de doutorado sobre a trajetória intelectual de Cascudo na PUC-SP, mas não abordou os condicionamentos sociais, culturais e institucionais dessa trajetória. Américo de Oliveira Costa ganhou um prêmio literário na Fundação José Augusto, órgão do governo estadual do Rio Grande do Norte com um trabalho, logo publicado, abordando a produção literária de Cascudo em várias áreas (CosTA, 1996). Muitos são os livros de panegírico à Cascudo. Remeto o leitor ao meu trabalho de doutorado, onde encontrará a referência de muitos deles. A produção acadêmica, apesar de não problematizar o seu objeto, tem fornecido análise mais complexas em pontos específicos. Veja-se Silva (2003), AraúJo (1995), Arrais (2005). 
se fazem sentir de diferentes modos. Não há, por exemplo, nas leituras que mistificam a figura de Cascudo onde a visão do "criador incriado"12 é muito difundida, a preocupação com a história nem com as fases que podem ser identificadas nessa produção intelectual. A produção parece se ligar à figura pessoal de Cascudo como um elemento estado ali desde sempre, desde o seu nascimento.

A cronologia da vida de Câmara Cascudo estabelece mais uma baliza de encaminhamento analítico através do espaço temporal social: de 1898 até 1986 . Esse período pode ser subdividido em muitas unidades características. Por exemplo, as publicações começaram no final da década de 1910 com artigos em jornais e o primeiro livro data de 1921. A produção de Cascudo na década de 1920 e 1930 se caracteriza pela prática de uma específica crítica literária, por escritos que explicitam perspectivas políticas, por uma historiografia biográfica personalista, por escritos relacionados a sua atividade como professor de história. O livro de 1939, Vaqueiros e cantadores: Folclore poético do sertão de Pernambuco, Paraíba, Rio Grande do Norte e Ceará (CASCUDO, 1984), representa o início de uma intensa fase de produção folclorista, que se estende da década de 1940 à década de 1970, produção que recebeu de Mário de Andrade um dos maiores incentivos iniciais como se constata nas várias informações que aparecem na correspondência entre os autores e em artigos e um ensaio sobre o folclore nacional. Na década de 1960 e 1970, Cascudo publica livros memorialísticos e outros que faz questão de caracterizar como etnográficos. Mas aparecem também, em cada uma dessas fases, escritos que podem ser relacionados a áreas mencionadas anteriormente. Por exemplo, a prática autodenominada histórica alcança maior extensão nos livros sobre a História da cidade do Natal, de 1948, e História do Rio Grande do Norte, de 1954. Muitos outros exemplos podem ser citados. Contudo, o fato do autor falecer em 1986 não encerra o período cultural de ação, tanto porque seus trabalhos foram publicados e republicados posteriormente, além do fato de que outros agentes no meio jornalístico, acadêmico e estatal realizaram publicações e eventos em sua referência e homenagem.

Proponho estudar a trajetória da produção intelectual de Luís da Câmara Cascudo. Essa produção, que apresenta aspectos unitários e particularidades de fases, também apresentou uma justaposição de ações de Cascudo no meio intelectual brasileiro e no meio social local, ampliando a força de sua presença. $\mathrm{O}$ local pode ser estabelecido pelo Rio Grande do Norte, pela cidade capital Natal,

12 A elaboração do mito do "criador incriado" pode ser observado nas elaborações de Bourdieu (1996). 
pelo círculo nordestino a partir de Recife, pelo meio cultural litorâneo e sertanejo. Particularmente no Rio Grande do Norte, a produção intelectual de Cascudo serviu também para um aumento de sua presença nas práticas culturais dos círculos dominantes e nas formas de poder social. A interação com o meio intelectual brasileiro acontece por meio de várias ações: pelo uso constante da correspondência (das mais importantes foi a com Mário de Andrade); com o fato de fazer cursos superiores morando em cidades como Salvador, Rio de Janeiro, Recife; com as publicações em periódicos do movimento modernista paulista; com as publicações na imprensa integralista na década de 1930; com as publicações de livros e artigos (a editora José Olympio aparece como uma das principais); com o envolvimento com o movimento de intelectuais folcloristas brasileiro ${ }^{13} \mathrm{e}$ por viagens constantes.

É possível imaginar sociologicamente ${ }^{14}$ um campo de poder numa sociedade como a do Rio Grande do Norte no século XX em suas diferentes conjunturas. Bourdieu desenvolve o conceito de campo de poder para dar conta das complexas relações entre os poderes de vários campos e a composição do poder na sociedade como um todo ${ }^{15}$. Mas, duas características próprias do nosso caso serve para matizar uma objetivação bem variada. Não temos a presença de muitos campos sociais bem diferenciados e a autonomia relativa é quase nula. Se temos agentes diferenciados como, por exemplo, um professor, um padre, um pai de família, um nome de família, um homem de partido, um chefe de governo, um procurador, um funcionário público, um poeta, um escritor, um advogado, um juiz, um médico, etc., suas ações, seus procedimentos, suas maneiras de viver, se misturam completamente no campo social realizando-se em grande dependência do que se passa na vida social do todo e particularmente pela força dominante das relações de poder estatal. Nesse sentido, tudo é mais simples e extremamente complexo, podendo se analisar o funcionamento de um único campo social constituindo a própria sociedade em sua totalidade. Um outro aspecto importante é a grande dependência das definições das relações locais de poder em relação ao centro do poder da sociedade nacional. Então, a autonomia relativa desse campo social também é muito tênue

13 Cf. o livro de Luís Rodolfo Vilhena que indica a existência de um movimento de intelectuais folcloristas e onde o nome de Luís da Câmara Cascudo ganha destaque (VilHenA,1997). As publicações de Cascudo na temática folclórica coincidem com o período tratado no livro de ascensão e queda do movimento nacional dos folcloristas.

14 A referência a uma imaginação sociológica remete de imediato ao livro de Mills (1975), que tem essa expressão já no próprio título. O interessante livro A imaginação sociológica fornece um grande incentivo para os processos de construção do objeto de pesquisa. Como na atividade de constituir relações: "A imaginação é levada, com freqüência, a reunir itens até então isolados, descobrindo ligações insuspeitadas” (Mills, 1975, p. 217).

15 Vide mais especificamente Bourdieu (1974). 
em relação à sociedade regional e mais permanentemente em relação à sociedade nacional em suas linhas culturalmente dominantes. Não podemos imaginar sociologicamente, nesse caso, a existência de um campo intelectual ${ }^{16}$, mesmo quando instituições escolares de nível superior se desenvolvem a partir das décadas de 1950 e 1960. Teremos atividades de produção e publicação de textos muito envolvidos com os outros aspectos da estrutura social local e nacional, fazendo circular um discurso de elite com funções explícitas de distinção social e justificando o caráter especial dessas elites. A interferência de movimentos nacionais também recebeu o forte filtro dos agentes locais do Rio Grande do Norte.

A imaginação sociológica deve procurar estabelecer a posição social do agente Cascudo num quadro de outras posições em movimento. Um primeiro elemento pode ser visto através da família. Se imaginarmos dois grandes grupos de família, os que tinham posses e se aproximavam do governo e aqueles sem posses e longe de partilhar as sociabilidades da primeira, identificamos Cascudo com o primeiro grupo familiar. Observar a família é ainda mais relevante aqui devido ao fato de que o poder se processava oligarquicamente com base nos grupos familiares. Se o núcleo principal da família é a dupla pai e mãe, no caso de Cascudo era o pai que aparecia como o polo forte de concentração e de dinâmica propositiva na vida externa ao círculo doméstico. O termo patriarcal, nem também o termo "masculino"17, não deve ser confundido na imaginação sociológica com estruturas de elementos substantivados, substituindo a vida social particular e as definições relacionais. Agora, no caso de Cascudo é a figura do pai que aparece totalmente como definidor de sua posição social e dos recursos necessários para entrar no jogo das coisas do espírito, como falam os agentes do meio. Acionando mecanismos sociais dos quais faz parte, o pai fornece todos os conjuntos de recursos que possibilitam à Cascudo a inserção no meio educacional, até aos cursos superiores de Medicina e Direito, e de outras atividades intelectuais no Brasil da época, como o incontornável jornalismo. Do pai vem os recursos necessários, também, para a publicação dos primeiros artigos em jornais, no jornal próprio $A$ Imprensa que o mesmo mantinha desde 1914, e para a publicação dos primeiros livros na década de 1920.

16 Lembro Sergio Miceli, que, na chamada qualificação do meu trabalho de doutorado, questionou a existência e, assim, a viabilidade da aplicação de um campo intelectual no espaço regional, já que não era o caso nem mesmo em São Paulo ou Rio de Janeiro, Estados que concentravam há décadas importantes movimentos culturais nacionais e os desenvolvimentos do mercado editorial. Veja-se, por exemplo, o estudo de Sorá (2010) sobre a editora José Olympio.

17 Vide as análises de Bourdieu em A dominação masculina (1999). 
Depois de concluído o curso de Direito, em 1928, Cascudo, que já partilhava das outras condições sociais necessárias, se credencia para uma série de funções com as quais acabará mesmo assumindo. Advoga para a Great Western, a empresa inglesa dona da rede ferroviária no Nordeste, e depois para o governo estadual; torna-se professor da principal instituição de ensino nas décadas de 1920 e 1930, o Atheneu, e depois diretor dessa instituição e da Diretoria de Ensino, que corresponde hoje ao cargo de Secretário da Educação. Chega, também, a ocupar cargo parlamentar tornando-se Deputado Estadual em 1930, embora passando apenas três dias devido ao movimento de outubro, que nessa conjuntura alijou do poder provisoriamente diversas oligarquias locais. Essas alocações que o credenciavam a diversos espaços na vida social também o levou à ação política mais direta em formas de organização coletiva: viveu intensamente o movimento integralista da década de 1930, fazendo parte da câmara dos quatrocentos. A cada momento da história de Cascudo podemos construir quadros institucionais, embora se possa identificar uma constância em sua posição relativa, sempre no espaço das classes superiores no interior das estruturas sociais e não desprovido de ações estratégicas por colocações e espaços de poder.

Nenhuma individualidade no campo da produção letrada no Rio Grande do Norte recebeu ou recebe tantos espaços propagandísticos nas últimas décadas quanto o nome de Câmara Cascudo. Ele próprio já fazia esse trabalho de divulgação constante do seu nome e do que escrevia. Comparou sua ação com o obstinado carrapato e o vaga-lume acendendo constantemente sua luz ${ }^{18}$. Depois de sua morte física, em 1986, processo que já acontecia desde a década de 1940, os agentes sociais que exerciam e exercem essa atividade de divulgação envolvem setores diversos: o mercado editorial de livros, que tem tido novo alento nos anos recentes; a imprensa escrita; diferentes setores das organizações estatais da divisão tradicional de poderes que podem receber nomeações mais precisas na Prefeitura

18 Um amigo de Cascudo de muitos anos escreveu um livro sobre ele. Ou melhor, organizou o livro Câmara Cascudo: um brasileiro feliz, que o próprio Cascudo conheceu e acompanhou antes da publicação. O mesmo é em sua quase totalidade uma reunião de fotos de Cascudo em diversos momentos da vida e com diferentes companhias e de pequenos pedaços de escritos e de registros orais que o amigo foi colecionando. Uma das partes se intitula "Os vaga-lumes de Cascudo" e se inicia com essa passagem: "Gentil, como de hábito, o Mestre foi me deixar no alto da escadaria de sua casa, de onde se via o Potengi. Diante de um grande e lustroso besouro que atravessava o nosso caminho, ele comentou: - O homem não tem nenhuma importância, importante mesmo é o besouro. Na melhor das hipóteses, o homem está na terra há 50 milhões de anos. Esta espécie está há 250 milhões. $\mathrm{O}$ homem pode destruir todas as baleias, todos os mamíferos, mas não consegue acabar com uma única classe de insetos. E quando o homem houver desaparecido, eles continuarão a voar sobre a terra. - Os besouros são apenas mais aptos ou mais importantes do que o homem? - Quando um homem é importante, é como eu, que imita os insetos. - O senhor imita insetos? - Pelo menos dois desses bichinhos: tenho a obstinação do carrapato e faço a publicidade e a autopromoção do vaga-lume" (LimA, 1998, p. 25). 
Municipal de Natal, no Governo Estadual do Rio Grande do Norte, e também no interior da Universidade Federal do Rio Grande do Norte, que tem um museu com o seu nome e um centro de estudos.

Essa ação de divulgação da individualidade de Câmara Cascudo chega também aos espaços físicos da cidade. Uma estátua do escritor em corpo inteiro ocupa praça no centro de Natal, em frente a um antigo prédio que se tornou em anos recentes o Memorial Câmara Cascudo, gerido pela Fundação José Augusto, órgão do governo estadual. Seu nome também aparece na fachada de outras edificações: uma estadual, a Biblioteca Pública Luís da Câmara Cascudo, outra federal, o Museu de Antropologia Câmara Cascudo da Universidade Federal do Rio Grande do Norte. Pouca é a preocupação em se discutir o conteúdo dos escritos ou o significado cultural do autor em suas relações com o mundo social local e nacional, mas em manter viva a sua memória. A denominação única que recebe Cascudo é a de "escritor", realizando-se nisso uma espécie de decantação social, onde outras camadas são submergidas, como a sua constante ação junto ao poder estatal. As referências à vida de Cascudo se reduzem àquelas atividades que se poderia chamar de "intelectuais": é o professor, o escritor, o orador, o poeta, o intelectual modernista, o folclorista, o historiador, o antropólogo, o sociólogo. O fato de que Cascudo construía bem suas amizades e tinha um carisma no diálogo e que também aparecia quando contava histórias em suas obras, é enfatizada na palavra francesa causeur.

As abordagens de autores como Câmara Cascudo podem ser incluídas numa investigação das condições sociais da produção letrada no Nordeste brasileiro no século XX. Nesse espaço aparecem muitos nomes conhecidos em diversas áreas de produção científica ou literária, memorialística, mas há muitos outros autores desconhecidos em diversos níveis e modalidades de produção intelectual. Podemos tentar observar dois grandes espaços que são sociais: o espaço do sertão e o espaço das cidades litorâneas capitais dos estados da região. Adicionalmente, os tipos de produção como a poesia, a memorialística, o romance e, em menores dimensões, o ensaio - seja ele histórico ou moral, com pretensões filosóficas. Câmara Cascudo, apesar de vários aspectos semelhantes no que escreveu e no modo como se motivou e se realizou essa atividade, tem suas características específicas dentro do quadro das diversas produções intelectuais no Nordeste. O limite regional aqui não diz respeito ao limite geográfico, uma vez que quase todos, senão todos, os intelectuais circularam em outros espaços sócio-geográficos e refletiram em si o que acontecia em outros espaços. Ao lembrar dos dois movimentos mais comentados - o do regionalismo e o do modernismo - vê-se que o aglutinador do movimento 
regionalista, Gilberto Freyre, tinha circulado e se doutorado nos Estados Unidos e o modernismo ressoava os acontecimentos artísticos internacionais.

Pode-se avaliar a existência de um conteúdo folclórico nos escritos aparentemente muito variados de Cascudo. Esses escritos têm muitas diferenças entre si ligados a uma micro-história ${ }^{19}$ e a uma microssociologia da trajetória do intelectual que pode ser construída em seus diversos momentos. O termo micro aqui subentende uma dimensão que é envolvida por outras mais abrangentes da sociedade e que entra na composição da construção do objeto necessária para a investigação científica. Mas, a despeito da identificação de modos específicos a determinadas fases, pode-se observar também diversos aspectos constantes que compõem, por sua vez, características de um específico social e histórico. A constância, também pode-se observar, não elimina a diferença em seu próprio seio. O folclorismo é observado como uma posição de amor às coisas produzidas pelo povo. Mas, essas "coisas produzidas pelo povo" assumem diversos níveis de problematização. Desde a completa ausência real desse agente "povo" ou das coisas que eles teriam produzido, até a redefinição da prática e da representação de determinados grupos nomeados como "popular" de acordo com as práticas e representações do tipo intelectual que realiza.

Os fatos que orientam a compreensão da história e da sociedade brasileira produzida por uma tradição intelectual, servem para oferecer uma lógica ao andamento e estruturação de fatos sociais e históricos da micro-história do Rio Grande do Norte. Uma questão é saber se são suficientes ou se nas especificidades locais se encontram elementos de importância inclusive hermenêutica. A vida social encontra-se nesses quadros locais. A importância como campo de exploração de análise científica é explícita. Pode, também, realmente contribuir com novas dosagens compreensivas de diversos aspectos apontadas em análises da sociedade brasileira em termos gerais.

\section{REFERÊNCIAS BIBLIOGRÁFICAS}

Araúso, Humberto Hermenegildo de. Modernismo: anos 20 no Rio Grande do Norte. Natal: Editora da UFRN, 1995.

Arrais, Raimundo. "O nascimento do cronista e o nascimento da cidade de Natal”. In: Cascudo, Luís da Câmara. Crônicas de origem: a cidade de Natal nas crônicas cascudianas dos anos 20. Natal: EDUFRN, 2005.

19 Conhecida no Brasil é a divulgação da micro-história por Carlo Ginzburg. Aqui penso remeter a esse autor em sua indicação da atenção ao detalhe que qualquer documento histórico pode fornecer. 
BACHELARD, Gaston. A formação do espírito científico: Contribuição para uma psicanálise do conhecimento. Rio de Janeiro: Contraponto, 1996. Estudos. Rio de Janeiro: Contraponto, 2008.

Bourdieu, Pierre. "Campo do poder, campo intelectual e habitus de classe". In: . $A$ economia das trocas simbólicas. São Paulo: Perspectiva, 1974. . As regras da arte: gênese e estrutura do campo literário. São Paulo: Companhia das Letras, 1996. . (coord.). A miséria do mundo. Petrópolis: Vozes, 1997. . A dominação masculina. Rio de Janeiro: Bertrand Brasil, 1999. . A distinção: uma crítica social da faculdade de juízo. Lisboa: Edições 70, 2010.

CARdoso, Rejane (coord.). 400 nomes de Natal. Natal: Prefeitura Municipal de Natal, 2000. CAscudo, Luís da Câmara (1984). Vaqueiros e cantadores. Belo Horizonte: Itatiaia; São Paulo: Universidade de São Paulo.

Cascudo, Luís da Câmara, Andrade, Mário de. Cartas, 1924-1944. São Paulo: Global, 2010. Costa, Américo de Oliveira. Viagem ao universo de Câmara Cascudo: tentativa de ensaio biobibliográfico. Natal: Fundação José Augusto, 1969.

Durkheim, Émile. Sociologia e filosofia. São Paulo: Ícone, 1994.

EuIAs, Norbert. A sociedade dos indivíduos. Rio de Janeiro: Jorge Zahar, 1994. . O processo civilizador. Rio de Janeiro: Jorge Zahar, 1994a. 2v. Mozart: sociologia de um gênio. Rio de Janeiro: Jorge Zahar, 1995. . Os alemães: a luta pelo poder e a evolução do habitus nos séculos XIX e XX. Rio de Janeiro: Jorge Zahar, 1997.

A sociedade de corte: investigação sobre a sociologia da realeza e da aristocracia de corte. Rio de Janeiro: Jorge Zahar, 2001.

Gico, Vânia. Luís da Câmara Cascudo: Bibliografia comentada: 1968/1995. Natal: EDUFRN, 1996.

Goffman, Erving. A representação do eu na vida cotidiana. Petrópolis: Vozes, 1999.

Gomes, Edna Maria Rangel de Sá. Correspondência: leitura das cartas trocadas entre Luís da Câmara Cascudo e Mário de Andrade. Universidade Federal do Rio Grande do Norte. Programa de Pós-graduação de Estudos da Linguagem. Dissertação de Mestrado. Natal, 1999.

Guanabara, Gileno. Faculdade de Direito de Natal: Lutas e tradições, 1949-1973. Natal: RN/Gráfica e Editora, 1988.

Lima, Diógenes da Cunha. Câmara Cascudo: um brasileiro feliz. 3 ed. Rio de Janeiro: Lidador, 1998. 
MAuss, Marcel. "Uma categoria do espírito humano: a noção de pessoa, a de 'eu' ”. In:

Sociologia e antropologia. São Paulo: Cosac \& Naify, 2003.

Melo, Manoel Rodrigues de et al. Luís da Câmara Cascudo: depoimentos: homenagem de seus amigos. Natal: Centro de Imprensa, 1947.

Melo, Veríssimo de (org.). Cartas de Mário de Andrade a Luís da Camara Cascudo. Belo Horizonte: Villa Rica, 1991.

Miceli, Sergio. Intelectuais à brasileira. São Paulo: Companhia das Letras, 2001. "Norbert Elias e a questão da determinação". In: WAIZBORT, Leopoldo (org.). Dossiê Norbert Elias. São Paulo: Edusp, 2001a.

Mills, Wright. A imaginação sociológica. 4. ed. Rio de Janeiro: Zahar, 1975.

Silva, Marcos (org.). Dicionário Crítico Câmara Cascudo. São Paulo: Perspectiva, FFLCH/ USP, Fapesp; Natal: Edufrn, Fundação José Augusto, 2003.

SoRÁ, Gustavo. Brasilianas: José Olympio e a gênese do mercado editorial brasileiro. São Paulo: Edusp; Com-Arte, 2010.

SouzA, Itamar de. Universidade: Para quê? Para quem? Natal: Clima, 1984.

Vilhena, Luís Rodolfo. Projeto e Missão: o movimento folclórico brasileiro (1947-1964). Rio de Janeiro: Funarte: Fundação Getúlio Vargas, 1997.

WACQUant, Loï J. D. "Durkheim et Bourdieu: le socle commun et sés fissures”, Critique, Tome LI, N. 579-580, août-septembre 1995.

WAizbort, Leopoldo. As aventuras de Georg Simmel. São Paulo: Ed. 34, 2000. 